\title{
Effect of High-Performance Liquid Chromatography Mobile Phase Components on Sensitivity in Negative Atmospheric Pressure Chemical Ionization Liquid Chromatography-Mass Spectrometry*
}

\author{
William H. Schaefer and Frank Dixon, Jr. \\ Department of Drug Metabolism and Pharmacokinetics, SmithKline Beecham Pharmaceuticals, King of \\ Prussia, Pennsylvania, USA
}

\begin{abstract}
We have investigated the effect of several common buffers (10-mM formic acid, $10-\mathrm{mM}$ ammonium acetate, and $100-\mathrm{mM}$ ammonium acetate) on the ionization of a series of model compounds that are amenable to negative atmospheric pressure chemical ionization to determine the extent of ionization quenching that can occur. In addition, we have compared the sensitivity of these standard mobile phases to a mobile phase that does not contain an acidic buffer component, but rather a base ( $N$-methylmorpholine). The results showed that, as expected, the sensitivity for the test analytes was greatest in the mobile phase that lacked acidic components. In general, ionization of analytes that contained a single, more weakly acidic functional group was inhibited to a greater degree by more strongly acidic buffer components. In some cases, ionization was quenched completely by acidic buffer components. Ionization of compounds that were more strongly acidic was quite good in all mobile phases tested. Differences in the ionization efficiencies of the analytes in each mobile phase were correlated with the gas-phase reagent ions present. As a point of reference, each of the analytes also was analyzed in the positive ion mode and the signal intensities were compared to those obtained in the negative ion mode. In addition, the utility of mobile phases that contained $\mathrm{N}$-methylmorpholine for chromatographic separations was demonstrated. (J Am Soc Mass Spectrom 1996, 7, 1059-1069)
\end{abstract}

\begin{abstract}
$\mathrm{A}$ tmospheric pressure ionization (API) methods used with liquid chromatography-mass spectrometry (LC-MS) have revolutionized trace analysis, which includes both quantitative and qualitative studies in chemical as well as biological sciences $[1,2]$. One area that has benefited dramatically from the advent of liquid chromatography-atmospheric pressure ionization-mass spectrometry (LC-API-MS) methodologies is bioanalytical chemistry. The high sensitivity and selectivity afforded by atmospheric pressure ionization methods with tandem mass spectrometry have decreased dramatically the time required for both method development and sample analysis, even when complex biological matrices such as plasma and urine are used.
\end{abstract}

Address reprint requests to Dr. William Schaefer, SmithKline Beecham Pharmaceuticals, 709 Swedeland Road (UW2711), King of Prussia, PA 19406.

*A preliminary account of this work was presented at the $43 \mathrm{rd}$ American Society of Mass Spectrometry Conference on Mass Spectrometry and Allied Topics in Atlanta (1995).
Atmospheric pressure chemical ionization (APCI) is used routinely for high throughput and high sensitivity quantitative LC-MS assays [3-8]. The chemical ionization process is initiated through a corona discharge and the high-performance liquid chromatography (HPLC) solvent components (and air) that are present in the source at relatively high pressure undergo a series of ion-molecule reactions and serve as chemical ionization reagents [9-11]. Ionization occurs primarily via proton transfer reactions and is driven by the gas-phase acidity or basicity of the reagent ions and the analytes [12-15]. Thus, development of optimal analytical conditions requires knowledge of the relative gas-phase proton affinities and acidities of the analyte and the HPLC mobile phase components. For efficient ionization in the positive ion mode, the analyte of interest should have a higher proton affinity than any of the HPLC mobile phase components.

Efficient ionization of amine-containing aliphatic compounds (which include many drugs) is generally not a problem. Ammonium acetate or ammonium for- 
mate buffers frequently are used to control the $\mathrm{pH}$ of the HPLC mobile phase for efficient chromatography, and ammonia has a lower proton affinity than substituted aliphatic amines. (Gas-phase proton affinity increases with increasing aliphatic substitution and increasing aliphatic chain length $[16,17]$.) Thus, ammonium reagent ions (and ammonium-solvent cluster ions) in the gas phase will transfer a proton to more basic amines (although one must be aware that ammonium-solvent cluster ions can have a lower gasphase acidity than unsolvated ammonium ions [13, 14]). Moreover, mobile phases that lack ammonia and contain dilute formic acid or acetic acid as $\mathrm{pH}$ modifiers can be used to help provide efficient positive ion formation of some analytes that possess a proton affinity lower than ammonia. Neutral molecules may not require any buffer components to yield acceptable chromatographic results. Thus, a variety of HPLC mobile phases are available that may provide good chromatography and relatively efficient ionization of a wide range of molecules in the positive ion mode.

Some molecules that have acidic functional groups inherently form negative ions with greater efficiency than positive ions. In these cases, analysis of negative ions offers the potential for greater sensitivity. However, the $\mathrm{pH}$ of HPLC mobile phases is generally $\leq 7$ due to instability of conventional silica-based HPLC columns at higher $\mathrm{pH}$. Thus, standard HPLC mobile phases often contain $\mathrm{pH}$ modifiers (which include acidic components) that can interfere with efficient ionization of analytes to form negative ions. For example, Fouda et al. [5] showed that the presence of ammonium acetate in the HPLC mobile phase decreased the negative APCI signal observed for a neutral renin inhibitor relative to that obtained by using only water-acetonitrile.

We have investigated the effect of several common HPLC buffer components on the ionization efficiency of a diverse series of model compounds that are amenable to APCI in the negative ion mode. In addition we have determined the gas-phase reagent ions that are produced with each of the HPLC mobile phases used. The goal was to determine the extent to which inappropriate mobile phases decrease ionization of analytes, as well as to establish guidelines to develop methods with optimal mobile phases. A better understanding of the interaction of solvent components with the ionization of analytes should facilitate more rational development of chromatography conditions that are amenable to highly sensitive analyses.

\section{Experimental Methods}

\section{Chemicals}

All of the analytes and buffer components used in this study were purchased from either Aldrich Chemical Co. (Milwaukee, WI) or Sigma Chemical Co. (St. Louis, MO). HPLC solvents were purchased from Baker (Phil- lipsburg, NJ) and pure water was obtained from a Milli-Q system (Millipore, Milford, MA).

\section{Sample Introduction and Mass Spectrometry}

These studies were conducted on a Sciex (PE-Sciex, Thornhill, Ontario) API III Plus triple quadrupole mass spectrometer using the atmospheric pressure chemical ionization (heated nebulizer) interface and a Hitachi (Hitachi Instruments, Danbury, CT) L-6000 binary pump system with a Rheodyne (Cotati, CA) manual injector fitted with a 5- $\mu \mathrm{L}$ sample loop.

The principal reagent ions in the gas phase were evaluated by Q1 full scan analysis over a range of $\mathrm{m} / \mathrm{z}$ 10-200 for each of the mobile phases in the positive and negative ion modes. Averaged spectra (10-20 scans) were obtained at a scan rate of $2 \mathrm{~s} / \mathrm{scan}$. The multiplier was decreased to $2900 \mathrm{~V}$ (compared to the normal setting of $3300 \mathrm{~V}$ ) to prevent saturation by the intense signals. The relatively complex mixture of components in each mobile phase provided numerous ions and ion-neutral clusters. Collision-induced dissociation spectra were obtained for the major ions (using a collision energy of $30 \mathrm{~V}$ and an argon collision gas thickness of $150 \times 10^{12}$ atoms $/ \mathrm{cm}^{2}$ ) to aid in structural assignments. An exact determination of the reagent ions in the API source was not possible because the ions must pass through the curtain gas to enter the mass analyzer. Because declustering occurs in this region, some of the cluster ions, which also serve as reagent ions, may be disrupted. Thus, the amounts of free (unclustered) ions detected may be higher than the actual amounts present in the source. The orifice was set to $-35 \mathrm{~V}$ for negative ions and 35 $\mathrm{V}$ for positive ions to minimize declustering.

To evaluate ionization efficiency, analytes were flow injected into the APCI source at a flow rate of 1 $\mathrm{mL} / \mathrm{min}$. All mobile phases for flow injections were composed of acetonitrile-aqueous buffer $(1: 1)$ because the analytes were soluble under these conditions. Although all of the mobile phases contained acetonitrile, for simplicity they were referred to throughout the text based on the buffer component. The buffers used are discussed in subsequent text. Each of the analytes was dissolved in the appropriate mobile phase prior to analysis. Because mixing of the injected sample with the mobile phase is sometimes minimal with flow injection analysis, the injection solvent can have a profound effect on the observed ionization efficiency. The hydroxamic acid samples were prepared in polypropylene tubes, because these compounds appeared to bind to glass containers.

The orifice potential and heated nebulizer temperature were optimized for each compound in each mobile phase. The orifice potential was optimized to provide maximum sensitivity with minimal fragmentation. An orifice potential of $-50 \mathrm{~V}$ was found to be optimal for all analytes in the negative ion mode except $\beta$-estradiol, which was optimized at $-70 \mathrm{~V}$. An 
orifice potential of $60 \mathrm{~V}$ was used for positive ion analyses. Variation of the temperature of the heated nebulizer within the normal operating range did not have much effect on the ionization of these compounds. Most experiments were done by using a heated nebulizer temperature of $450{ }^{\circ} \mathrm{C}$. A few of the compounds showed a slightly improved signal with the formic acid mobile phase using a temperature of $480^{\circ} \mathrm{C}$. The nebulizing gas (air) was adjusted to $70 \mathrm{psi}$ and the auxiliary gas was delivered at $1 \mathrm{~L} / \mathrm{min}$. Changing the gas flow rates did not have a significant effect on sensitivity.

Five sequential 5- $\mu \mathrm{L}$ injections (containing $2 \mathrm{pmol}$ each) were made for each analyte in each mobile phase followed by two blank injections that contained only mobile phase to ensure that the observed signal was not an artifact of the injection. The mass spectrometer was operated in selected ion monitoring (SIM) mode with a dwell time of 200-ms to monitor the $\left[\mathrm{M}-\mathrm{H}^{-}\right.$ or the $[\mathrm{M}+\mathrm{H}]^{+}$for each compound for negative and positive ion analyses, respectively. The area of each peak (above the baseline noise) was determined using the Sciex MacQuan software.

\section{Chromatography}

The chromatographic behavior of several compounds was investigated using amine-containing mobile phases with a 4.6- $\times 150-\mathrm{mm}$ Aluspher $\mathrm{C} 8$ column (EM Science, Gibbstown, NJ). Three different amine modifiers were used under gradient conditions. Solvent A was an aqueous solution that contained $10-\mathrm{mM} \mathrm{N}$ methylmorpholine, triethylamine, or ammonia, each at its natural $\mathrm{pH}(9.6,11.0$, and 11.1 , respectively); solvent $B$ was acetonitrile. At the beginning of the gradient, the mobile phase consisted of $100 \%$ solvent $A$; solvent $B$ was increased at a rate of $3 \%$ per minute. The flow rate was $1 \mathrm{~mL} / \mathrm{min}$. Each analyte was detected as its $[\mathrm{M}-\mathrm{H}]^{-}$by using negative APCI and selected ion monitoring as described in the preceding text. The heated nebulizer was operated at $450{ }^{\circ} \mathrm{C}$ with the nebulizer gas set to $70 \mathrm{psi}$ and an auxiliary gas flow of $1 \mathrm{~L} / \mathrm{min}$. The orifice was set to $-50 \mathrm{~V}$.

\section{Results and Discussion}

\section{General Strategy}

Compound selection strategy. The objective of the study was to evaluate the ionization of compounds that contain functional groups that are commonly encountered in pharmaceuticals and are candidates for analysis in the negative ion mode. These functional groups included carboxylic acids, hydroxamic acids, and phenols. The seemingly unusual collection of test analytes shown in Table 1 was selected based on several criteria. The compounds had to be of relatively high molecular weight so that their $\left[\mathrm{M}-\mathrm{H}^{-}\right.$ions were above most of the low mass solvent noise. The carboxylic and hydroxamic acids that were selected ranged from aliphatic to aromatic to cover a range of acidic strengths. One group of compounds that contained only one protic functional group was selected to avoid any additive or interfering effects of additional protic functional groups. Additional compounds that did have multiple functional groups were analyzed to compare their responses relative to those with only one acidic functional group, as well as to compare ionization in both positive and negative modes. Finally, all of the analytes had to be commercially available.

Solvent selection strategy. The ionization efficiency (or signal intensity) of each of the test analytes was investigated using mobile phases composed of buffers that are frequently used for LC-APCI-MS. These buffers included 10- and $100-\mathrm{mM}$ ammonium acetate $(\mathrm{pH} 6.8$, the natural $\mathrm{pH}$ ), which were selected to investigate the effect of acetic acid at low and high concentrations. Formic acid (10 mM), which is commonly used as an alternative to trifluoroacetic acid, was used to test the effect of a stronger acid on negative ion formation. A mobile phase that lacked an acidic modifier was sought and was expected to yield the maximum signal because it would provide minimum competition for ionization. A mixture of water and acetonitrile was considered, but this mobile phase (which lacked a buffer) would not support reverse phase chromatography of acidic compounds. Mobile phases that contained various amines, including ammonia, triethylamine, and $\mathrm{N}$-methylmorpholine, also were considered. $\mathrm{N}$-methylmorpholine was selected because it is a volatile, nonnucleophilic base and providing the best column retention. (It should be noted that we also found that the aqueous $N$-methylmorpholine-acetonitrile mobile phase was more effective toward cleaning residues from the heated nebulizer than the more conventional mobile phases.) The $\mathrm{pH}$ of the mobile phases should not effect the APCI process because the mobile phase and analytes are evaporated into the gas phase as neutral molecules (and clusters). Thus the chemical nature of the compounds in the HPLC effluent and their relative quantities are most important.

\section{Optimization of Mass Spectrometer Source Conditions}

Although the optimal heated nebulizer conditions (temperature, and nebulizer and auxiliary gas flow rates) did not vary significantly for the different compounds, the orifice potential was found to have a profound effect on the observed fragmentation of some analytes. Aryl acetic acids, such as ibuprofen, diclofenac, and indomethacin, tended to lose $\mathrm{CO}_{2}$ readily at higher orifice potentials in the negative ion mode, perhaps driven by the stability of the resulting benzylic anion. For example, mass spectra for diclofenac are shown in Figure 1 at orifice potentials of 


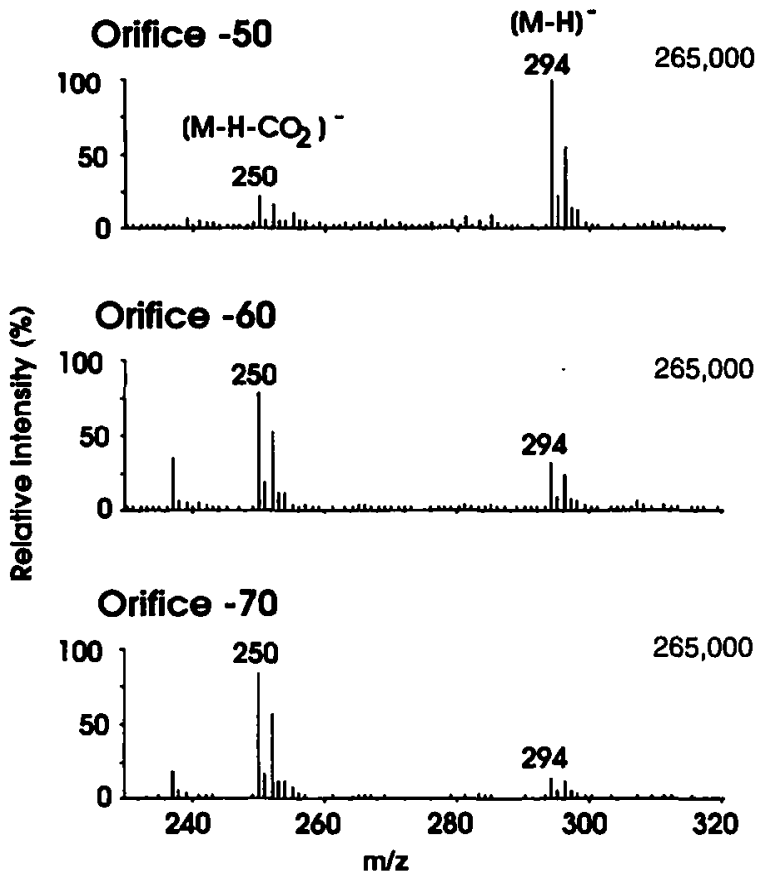

Figure 1. Negative APCI mass spectra of diclofenac $\left([\mathrm{M}-\mathrm{H}]^{-}\right.$ at $m / z 294)$ at orifice potentials of $-50,-60$, and $-70 \mathrm{~V}$ obtained using the $N$-methylmorpholine mobile phase. The value in the upper right corner of each spectrum represents signal intensity (full scale).

$-50,-60$, and $-70 \mathrm{~V}$. The $[\mathrm{M}-\mathrm{H}]^{-}$ion was predominant at $-50 \mathrm{~V}$, but was much less intense than the $\left[\mathrm{M}-\mathrm{H}-\mathrm{CO}_{2}\right]^{-}$ion at $-70 \mathrm{~V}$. Acetylsalicylic acid was also quite labile and displayed significant elimination of $\mathrm{CH}_{2} \mathrm{CO}$ even at an orifice potential of $-50 \mathrm{~V}$.

\section{Characterization of Negative Reagent Ions Formed in the Source}

Figure 2 displays the mass spectra of the low mass region that contains the reagent ions for each of the mobile phases used. The principal reagent ion formed with the $\mathrm{N}$-methylmorpholine mobile phase was superoxide anion $\left(\mathrm{O}_{2}^{-} ; \mathrm{m} / z\right.$ 32). The formation of superoxide from oxygen in the carrier gas in the presence of a corona discharge is well known [18-20]. The spectrum also showed ions at $m / z \quad 45$ and 59 that were assigned to formate and acetate, respectively. The formate and acetate signals could not be reduced even with extensive washing of the HPLC system. An ion at $m / z$ 42, which could represent cyanate (or azide), was observed, but the identity and source of this ion was not proven. Each of these ions has a lower gas-phase basicity [as represented by a smaller Gibbs free energy $\Delta G_{\text {acid }}(\mathrm{AH})$ for the reaction of the conjugate acid $\left.\mathrm{AH} \rightarrow \mathrm{A}^{-}+\mathrm{H}^{+}\right]$than superoxide (see Table 2), which indicates that superoxide was the primary reagent ion. The acetonitrile anion $(m / z 40)$ was not observed and would not be expected in the presence of excess super-
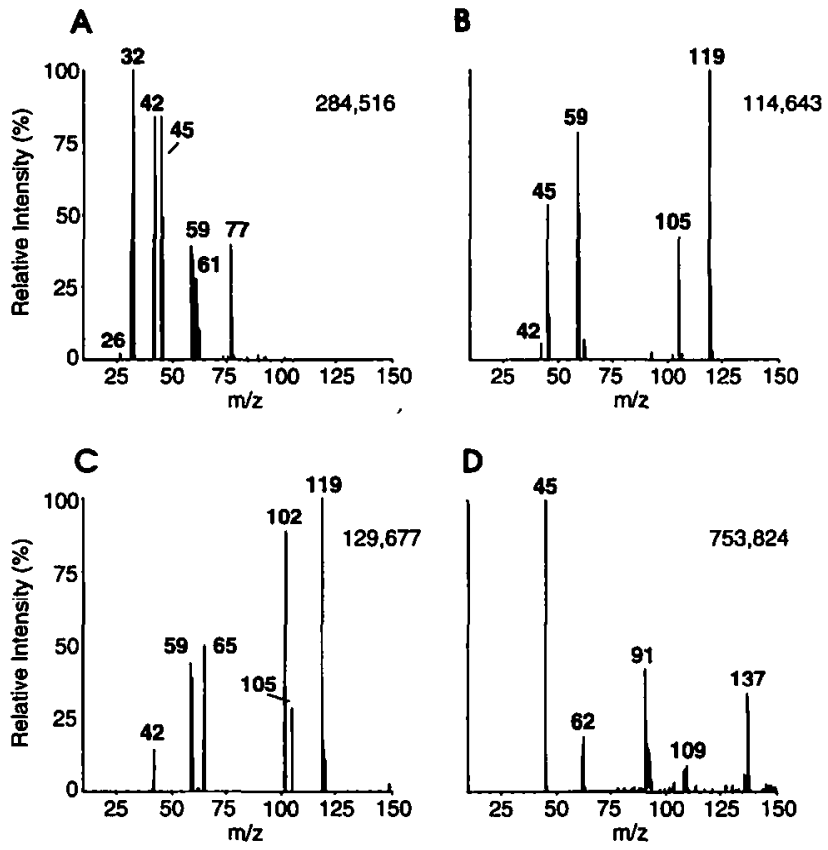

Figure 2. Negative APCI mass spectra of the reagent ions produced from a 1:1 mixture of acetonitrile with the following aqueous buffers: (A) $10-\mathrm{mM} N$-methylmorpholine, (B) $10-\mathrm{mM}$ ammonium acetate, (C) $100-\mathrm{mM}$ ammonium acetate, or (D) 10mM formic acid.

oxide because acetonitrile anion is the stronger gasphase base. Acetonitrile would not transfer a proton to superoxide anion. The reagent ion spectrum from the $\mathrm{N}$-methylmorpholine mobile phase was qualitatively and quantitatively the same as that obtained for $50 \%$ aqueous acetonitrile, which indicates that $\mathrm{N}$-methylmorpholine did not contribute significantly to reagent ion formation. Although clusters of superoxide with water have been reported [20], no clusters of superoxide with any of the mobile phase components were observed with either of these mobile phases.

The reagent ion spectrum of the $10-\mathrm{mM}$ ammonium acetate mobile phase displayed a variety of ions (Figure $2 b$ ). Acetate was observed at $m / z 59$ and an acetic acid-acetate cluster was observed at $m / z 119$. Formate was also observed at $m / z 45$, as well as an acetic acid-formate cluster at $m / z 105$. The source of the formic acid was not determined and, as before, extended washing of the HPLC system did not remove or diminish the formic acid signals. The presence of formic acid in the ammonium acetate buffer or acetonitrile could not be ruled out. A very small signal also was observed at $m / z 42$ as described previously. Although superoxide also likely was generated as a primary reagent ion from the corona discharge in the presence of oxygen in the source, it apparently reacted with the excess acetic acid via proton transfer $\mathrm{O}_{2}^{-}+$ $\mathrm{AcOH} \rightleftharpoons \mathrm{O}_{2} \mathrm{H}+\mathrm{AcO}^{-}$) to generate acetate (and acetate clusters) as a secondary reagent ion(s).

The reagent ion spectrum for $100-\mathrm{mM}$ ammonium acetate (Figure 2c) displayed acetate at $\mathrm{m} / \mathrm{z} 59$ and an acetic acid-acetate cluster at $m / z 119$ that was much 
more abundant. (A bis-acetic acid-acetate cluster was not detected.) A signal was observed at $m / z 42$, as well as an intense ion at $m / z 102$ that represented an acetic acid cluster of the $m / z \quad 42$ ion. A signal for formate was not observed, although a weak signal for an acetic acid-formate cluster at $m / z 105$ was present. The ion at $m / z 65$ was not identified. The relatively high concentration of ammonium acetate in this mobile phase resulted in a high partial pressure of acetic acid in the gas phase and thus yielded a higher proportion of acetic acid clusters than was observed with 10-mM ammonium acetate. Apparently, the ionization process was insufficient to deprotonate all of the acetic acid molecules in the source (to form free acetate ions only). The quantity of free acetate ions $(m / z 59)$ displayed in the spectrum (for both $10-$ and $100-\mathrm{mM}$ ammonium acetate) may be larger than the actual amount in the source due to the declustering that occurred in the curtain gas region.

The principal ions displayed by the formic acid mobile phase (Figure $2 \mathrm{~d}$ ) were formate $(m / z 45)$, a formic acid-formate cluster $(m / z 91)$, and a bis-formic acid-formate cluster $(m / z 137)$.

\section{Effect of Mobile Phase Buffers on Negative Ion Sensitivity}

Four simple carboxylic acid compounds with increasing acidity (2-norbornaneacetic acid, 3-(4-methoxyphenyl)propionic acid, ibuprofen, and acetylsalicylic acid) were selected initially. An example of the data obtained for 2-norbornaneacetic acid is shown in Figure 3 . The area of each peak (above the background noise) was determined and a summary of the results for the entire series of analytes is shown in Table 1. The actual mean peak area and standard deviation values also are shown in parentheses. The mean peak area value for each analyte in each mobile phase was normalized relative to that observed by using $N$-methylmorpholine $(100 \%)$. In all cases, $N$-methylmorpholine yielded the most efficient ionization and the relatively strongly acidic formic acid showed the greatest inhibition of ionization. Of the four carboxylic acids in the foregoing list, those that were weaker acids were effected more dramatically by the acidic buffer components. The gas-phase acidity $\left[\Delta G_{\text {acid }}(A H)\right]$ of acetic acid is $1429 \mathrm{~kJ} / \mathrm{mol}$ [17] and the acidity of aliphatic carboxylic acids tends to increase slightly with increasing alkyl chain length (see Table 2 and refs 17, 22, and 23). Phenylacetic acid is more acidic than the aliphatic carboxylic acids and benzoic acid shows even greater gas-phase acidity. Thus, the acidity of carboxylic acidcontaining analytes tested can be assumed to increase according to 2-norbornaneacetic acid < 3-(4-methoxyphenyl)propionic acid < ibuprofen < acetylsalicylic acid, and the efficiency of ionization in the presence of acetate increased in the same order. The more weakly acidic carboxylic acids, 2-norbornaneacetic acid, 3-(4methoxyphenyl)propionic acid, and ibuprofen, showed
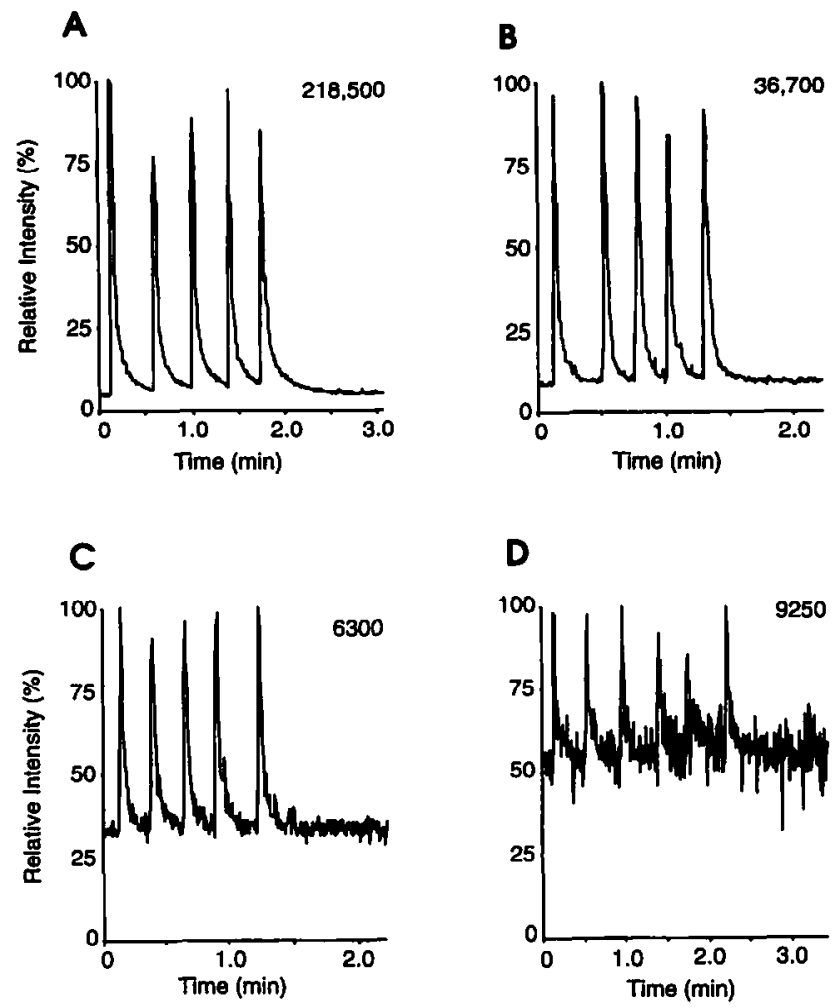

Figure 3. Reconstructed ion traces for the $[\mathrm{M}-\mathrm{H}]^{-}$at $m / z 153$ for 2-norbornaneacetic acid obtained using HPLC mobile phases composed of a 1:1 mixture of acetonitrile with the following aqueous buffers: (A) $10-\mathrm{mM} \quad \mathrm{N}$-methylmorpholine, (B) $10-\mathrm{mM}$ ammonium acetate, (C) $100-\mathrm{mM}$ ammonium acetate, or (D) 10 $\mathrm{mM}$ formic acid. The value in the upper right corner of each trace represents signal height.

more inhibition of ionization with the $100-\mathrm{mM}$ ammonium acetate buffer than with $10-\mathrm{mM}$ ammonium acetate. In the presence of the formic acid mobile phase, ionization of these aliphatic carboxylic acids was decreased dramatically. Ionization of the benzoic acid-derived compound (acetylsalicylic acid) was decreased to 28 and $42 \%$ in $10-$ and $100-\mathrm{mM}$ ammonium acetate, respectively. Formic acid decreased the ionization of acetylsalicylic acid to only $14 \%$ of that observed by using $N$-methylmorpholine.

The hydroxamic acid-containing compounds yielded results that were similar to those obtained for the carboxylic acids. The strongly electron-withdrawing trifluoromethyl group of trifluoromethoxybenzohydroxamic acid appeared to have increased the acidity of the hydroxamic acid such that acetate did not inhibit the ionization of this compound appreciably. Even with the electron deficiency expected for this structure, an $[\mathrm{M}-\mathrm{H}]^{-}$was formed rather than an $\mathrm{M}^{-\cdot}$ via electron capture.

The phenol-containing compounds also displayed a similar profile. Although the greatest signal was observed using the $N$-methylmorpholine mobile phase, the response was somewhat less than many of the carboxylic acid and hydroxamic acid compounds. Because HPLC separations of phenolic compounds gen- 
Table 1. Comparison of the ionization of model compounds by negative ion APCI in the presence of various buffers (mixed with acetonitrile $1: 1)^{\mathrm{a}}$

\begin{tabular}{|c|c|c|c|c|c|}
\hline Compound & {$[M-H]^{-}$} & $\begin{array}{l}N \text {-Methyl } \\
\text { morpholine } \\
(10 \mathrm{mM})\end{array}$ & $\begin{array}{l}\text { Ammonium } \\
\text { acetate } \\
(10 \mathrm{mM})\end{array}$ & $\begin{array}{c}\text { Ammonium } \\
\text { acetate } \\
(100 \mathrm{mM})\end{array}$ & $\begin{array}{l}\text { Formic acid } \\
(10 \mathrm{mM})\end{array}$ \\
\hline $\begin{array}{l}\text { 2-Norbornaneacetic } \\
\text { acid }\end{array}$ & 153 & $\begin{array}{c}100 \% \\
(58.6 \pm 5.9)\end{array}$ & $\begin{array}{c}14 \% \\
(8.49 \pm 0.44)\end{array}$ & $\begin{array}{c}2 \% \\
(0.96 \pm 0.12)\end{array}$ & $\begin{array}{c}1 \% \\
(0.85 \pm 0.11) \\
{[1.5]^{b}}\end{array}$ \\
\hline
\end{tabular}

\section{3-(4-Methoxyphenyl)-}

propionic acid<smiles>COc1ccc(CCC(=O)O)cc1</smiles>

179

$100 \% \quad 47 \%$

$(42.6 \pm 2.9)$

$(19.8 \pm 2.1)$

$5 \%$

$(2.3 \pm 0.45)$

$2 \%$

$(0.64 \pm 0.07)$

[0.73]<smiles>CC(C)Cc1ccc(C(C)C(=O)Oc2ccccc2C(=O)Oc2ccccc2C(C)(C)C)cc1</smiles>

205

$100 \%$
$(34.0 \pm 5.0)$

$96 \%$

$(32.6 \pm 1.5)$

$10 \%$

$(3.3 \pm 0.27)$

$3 \%$

$(0.97 \pm 0.21)$

[2.4]

Acetylsalicylic acid

179

$100 \%$

$(26.8 \pm 1.5)$

$28 \%$

$(7.6 \pm 0.94)$

$42 \%$

$\{11.3 \pm 2.2\}$

$14 \%$

$3.8 \pm 0.47)$

[3.5]

$\beta$-Estradiol

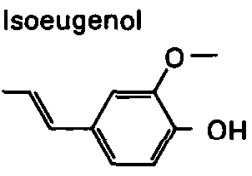

163

$100 \%$

$(9.8 \pm 1.1)$

$6 \%$

$(0.58 \pm 0.14)$

$4 \%$

$1 \%$

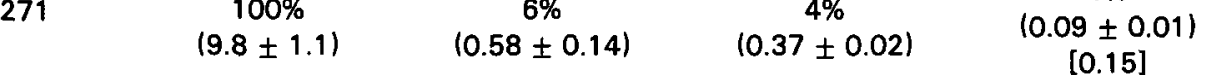

[0.15]

\section{4-Methoxyhydro-}

cinnamyl

hydroxamic acid<smiles>COc1ccc(CCC(=O)NO)cc1</smiles>

194

$100 \%$

$(14.0 \pm 0.21)$

$30 \%$

$(4.2 \pm 0.24)$

$9 \%$

$(1.2 \pm 0.09)$

$1 \%$

$<1 \%$

$(15.5 \pm 1.3)$

$8 \%$
$(1.2 \pm 0.09)$

$(0.50 \pm 0.15)$

[1.1]

$$
\begin{gathered}
\text { Benzohydroxamic } \\
\text { acid }
\end{gathered}
$$

4-Trifluoromethoxybenzohydroxamic acid<smiles>O=C(NO)c1ccc(C(=O)OC(F)(F)F)cc1</smiles>

220

136

$100 \%$
$(26.8 \pm 1.9)$

$66 \%$

$(17.6 \pm 1.4)$

$11 \%$
$(3.0 \pm 0.26)$

$<1 \%$

[0.29] 
Table 1. Comparison of the ionization of model compounds by negative ion APCI in the presence of various buffers (mixed with acetonitrile $1: 1)^{\mathbf{a}}$ (continued)

\begin{tabular}{|c|c|c|c|c|c|}
\hline Compound & {$\left[\mathrm{M}-\mathrm{H}^{-}\right.$} & $\begin{array}{l}N \text {-Methyl } \\
\text { morpholine } \\
\text { (10 mM) }\end{array}$ & $\begin{array}{c}\text { Ammonium } \\
\text { acetate } \\
(10 \mathrm{mM})\end{array}$ & $\begin{array}{c}\text { Ammonium } \\
\text { acetate } \\
(100 \mathrm{mM})\end{array}$ & $\begin{array}{l}\text { Formic acid } \\
(10 \mathrm{mM})\end{array}$ \\
\hline $\begin{array}{l}\text { Piperidinep } \\
\text { acid }\end{array}$ & 156 & $\begin{array}{c}100 \% \\
(20.9 \pm 0.46)\end{array}$ & $\begin{array}{c}17 \% \\
(3.5 \pm 0.38)\end{array}$ & $\begin{array}{c}2 \% \\
(0.39 \pm 0.06)\end{array}$ & $\begin{array}{l}<1 \% \\
\text { [ND] }\end{array}$ \\
\hline & 294 & $\begin{array}{c}100 \% \\
(30.3 \pm 2.7)\end{array}$ & $\begin{array}{c}63 \% \\
(19.1 \pm 2.3)\end{array}$ & $\begin{array}{c}77 \% \\
(23.3 \pm 3.2)\end{array}$ & $\begin{array}{c}78 \% \\
(23.6 \pm 0.93) \\
{[9.2]}\end{array}$ \\
\hline & 356 & $\begin{array}{c}100 \% \\
(15.0 \pm 0.42)\end{array}$ & $\begin{array}{c}50 \% \\
(7.5 \pm 0.85)\end{array}$ & $\begin{array}{c}83 \% \\
(12.4 \pm 0.57)\end{array}$ & $\begin{array}{c}47 \% \\
(7.1 \pm 1.0) \\
{[1.3]}\end{array}$ \\
\hline
\end{tabular}

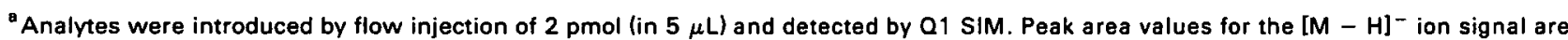
expressed as a percent, relative to areas observed using $\mathbf{N}$-methylmorpholine. The absolute average peak area values also are shown in parentheses (average area \pm st. dev. $\times 10^{-4}$ ).

${ }^{b}$ The values in brackets (under Formic acid) represent the peak area ratios observed for the signals for the deprotonated analyte relative to the analyte-formate cluster $[\mathrm{M}-\mathrm{H}]-/\left[\mathrm{M}+\mathrm{HCO}_{2}^{-}\right]$; $\mathrm{ND}=$ not determined.

Table 2. Gas-phase acidities (to form $\left[\mathrm{M}-\mathrm{H}^{-}\right.$ions) and proton affinities (to form $[\mathrm{M}+\mathrm{H}]^{+}$ions) for reference compounds (data from ref 17)

\begin{tabular}{|c|c|c|}
\hline Compound & $\begin{array}{c}\Delta G_{\text {acid }}(\mathrm{AH}) \\
(\mathrm{kJ} / \mathrm{mol})\end{array}$ & $\begin{array}{l}\text { Proton affinity } \\
(\mathrm{kJ} / \mathrm{mol})\end{array}$ \\
\hline $\mathrm{NH}_{3}$ & 1657 & 854 \\
\hline $\mathrm{CH}_{3} \mathrm{NH}_{2}$ & 1656 & 896 \\
\hline $\mathrm{CH}_{3} \mathrm{CH}_{2} \mathrm{NH}_{2}$ & 1639 & 908 \\
\hline$\left(\mathrm{CH}_{3}\right)_{2} \mathrm{NH}$ & 1628 & 923 \\
\hline $\mathrm{H}_{2} \mathrm{O}$ & 1607 & 697 \\
\hline $\mathrm{CH}_{3} \mathrm{CN}$ & 1528 & 787 \\
\hline $\mathrm{O}_{2} \mathrm{H}$ & 1449 & $N A^{a}$ \\
\hline $\mathrm{HCN}$ & 1438 & 717 \\
\hline Phenol & 1432 & 821 \\
\hline $\mathrm{CH}_{3} \mathrm{COOH}$ & 1429 & 796 \\
\hline $\mathrm{CH}_{3} \mathrm{CH}_{2} \mathrm{COOH}$ & 1424 & 802 \\
\hline $\mathrm{CH}_{3} \mathrm{CH}_{2} \mathrm{CH}_{2} \mathrm{COOH}$ & 1420 & $N^{a}$ \\
\hline $\mathrm{CH}_{3} \mathrm{CH}_{2} \mathrm{CH}_{2} \mathrm{CH}_{2} \mathrm{COOH}$ & 1419 & $\mathrm{NA}^{\mathrm{a}}$ \\
\hline $\mathrm{CH}_{3} \mathrm{CH}_{2} \mathrm{CH}_{2} \mathrm{CH}_{2} \mathrm{CH}_{2} \mathrm{COOH}$ & 1418 & $N A^{a}$ \\
\hline HNCO & 1415 & 725 \\
\hline $\mathrm{HCOOH}$ & 1415 & 748 \\
\hline Phenylacetic acid & 1398 & $N^{a}$ \\
\hline Benzoic acid & 1388 & 829 \\
\hline Trifluoroacetic acid & 1323 & 707 \\
\hline
\end{tabular}

'NA = data not available from ref 17. erally can be accomplished without buffers or $\mathrm{pH}$ modifiers in the mobile phase, the response of $\beta$ estradiol and isoeugenol using water-acetonitrile $(1: 1)$ was evaluated. The response for isoeugenol was essentially equivalent with water or aqueous $N$-methylmorpholine. For $\beta$-estradiol, the response with water was approximately $65 \%$ of that obtained with aqueous $N$ methylmorpholine.

As described in the preceding text, the use of a mobile phase that contains formic acid generally diminishes the formation of $[\mathrm{M}-\mathrm{H}]^{-}$ions. We considered the possibility that formate clusters $\left[\mathrm{M}+\mathrm{HCO}_{2}^{-}\right]$ might be formed instead of $[\mathrm{M}-\mathrm{H}]^{-}$ions under these conditions. Many of the analytes did in fact form formate clusters. The peak area of the signal for the $[\mathrm{M}-\mathrm{H}]^{-}$ion relative to that of the analyte-formate cluster ranged from 0.29 to 9.2 (Table 1). However, in all cases the signal for the formate cluster ([M + $\left.\mathrm{HCO}_{2}^{-}\right]$) was still much lower than that observed using ammonium acetate or $\mathrm{N}$-methylmorpholine. No obvious correlation was apparent between the amount of formate cluster detected and the structure or acidity of the analyte.

A group of analytes was chosen that contained multiple functional groups that could readily form negative and/or positive ions. These compounds were evaluated to determine whether multiple functional groups would enhance negative ion formation (e.g., through additive or synergistic effects) or whether the 
presence of functional groups that readily accept a positive charge would decrease the formation of negative ions elsewhere on the molecule. Formation of negative ions by piperidinepropionic acid, which contains an aliphatic carboxyl group and a tertiary amine, was similar to that of the other aliphatic carboxylic acid 2-norbornaneacetic acid in each of the test mobile phases. Acidic modifiers in the mobile phase dramatically decreased $[\mathrm{M}-\mathrm{H}]^{-}$ion formation (Table 1 ). In contrast, diclofenac, which contains an electrondeficient amine and a phenyl acetic acid moiety, formed negative ions with reasonable efficiency in all of the mobile phases tested. Indomethacin, which contains a substituted amide and an aryl acetic acid moiety, also formed negative ions moderately well in the presence of acidic modifiers. The strong responses of diclofenac and indomethacin in each of the acidic mobile phases was not expected based on their structures. The electron-withdrawing nature of the aryl substituents of diclofenac and indomethacin appeared to result in increased acidity relative to ibuprofen.

The foregoing ionization results for analytes that contain a single protic functional group were consistent with those that might be expected based on the gas-phase acidities of model compounds (see Table 2). The superoxide anion was sufficiently basic to abstract a proton readily from any of the analytes tested. Thus, efficient ionization was observed using the $N$-methylmorpholine mobile phase where the superoxide anion was predominant. Formic acid, however, is quite acidic ( $1415 \mathrm{~kJ} / \mathrm{mol})$ and more acidic than acetic acid (or even hexanoic acid). Since stronger acids have weaker conjugate bases, formate ion is a weaker base and, thus, a weaker gas-phase reagent ion than acetate. Only the strongest acids tested were ionized efficiently in the presence of the formic acid mobile phase. Interestingly, the gas-phase acidity of phenol $(1432 \mathrm{~kJ} / \mathrm{mol})$ is only slightly less than that of acetic acid, but much greater than that of water $(1607 \mathrm{~kJ} / \mathrm{mol})$ [although in solution, the acidity of phenol $\left(\mathrm{p} K_{a} \sim 10.0\right)$ is weaker than that of water $\left(\mathrm{p} K_{a}\right.$ 7.0)]. This corroborates the observation that the ionization of phenols was not quenched in the presence of water (even though water is present is a tremendous molar excess) or even totally quenched in the presence of acetic acid. Trifluoroacetic acid, which frequently is used as a chromatographic modifier, displays a very strong gas-phase acidity $(1323 \mathrm{~kJ} / \mathrm{mol})$ consistent with its relatively high acidity in solution and would yield a very poor (weakly basic) gas-phase reagent ion. For weaker acids, such as 2-norbornaneacetic acid, 3-(4-methoxyphenyl) propionic acid, ibuprofen, and 4-methoxyhydrocinnamyl hydroxamic acid, the $10-\mathrm{mM}$ ammonium acetate mobile phase showed better production of [M $\mathrm{H}]^{-}$ions than $100-\mathrm{mM}$ ammonium acetate. This could be due to the increased concentration of free acetate ions present at $10 \mathrm{mM}$ compared to the predominance of acetic acid-acetate cluster ions at $100 \mathrm{mM}$. Because free acetate is expected to be a stronger base than the acetate clusters due to stabilization of the acetate anion by hydrogen bonding $[13,14,24]$, the free acetate ions may be able to abstract a proton from these relatively weakly acidic analytes, but the acetate clusters may not be sufficiently basic to react. In addition, because the basicities of the analyte anions and the acetate reagent ions are quite similar, the proton transfer reaction is likely to proceed via a thermodynamically controlled reversible reaction, rather than a rapid reaction under kinetic control [13-15]. Based on results obtained with positive ions [13-15], ionization in the negative mode could proceed via the reversible reaction $\mathrm{AH}+\mathrm{AcO}^{-} \rightleftharpoons \mathrm{A}^{-}+\mathrm{AcOH}$ [or $\mathrm{AH}+$ $(\mathrm{AcOH}) \mathrm{AcO}^{-} \rightleftharpoons \mathrm{A}^{-}(\mathrm{AcOH})+\mathrm{AcOH}$ with subsequent dissociation of $\mathrm{A}^{-}(\mathrm{AcOH})$ to yield the analyte anion $\mathrm{A}^{-}$], which reaches equilibrium in the source. The increased acetic acid concentration in the source with the $100-\mathrm{mM}$ ammonium acetate buffer (relative to $10 \mathrm{mM}$ ) would tend to drive the reverse reaction and diminish analyte ion formation. Interestingly, for analytes that appeared to have a higher gas-phase acidity (such as acetylsalicylic acid, diclofenac, indomethacin, and trifluoromethoxybenzohydroxamic acid) the increased ammonium acetate concentration (100 mM) improved ionization relative to $10-\mathrm{mM}$ ammonium acetate, perhaps due to increased proton abstraction by free acetate, as well as by acetate-solvent clusters.

Alternatively, the high concentration of acetate in the source with $100-\mathrm{mM}$ ammonium acetate could result in preferential production of acetate clusters rather than $[\mathrm{M}-\mathrm{H}]^{-}$ions. Formation of clusters was evaluated by using only the $10-\mathrm{mM}$ formic acid mobile phase. Since formate cluster ions were observed with many of the analytes tested, the potential for formation of acetate adducts (in the presence of ammonium acetate) also seems possible and should be evaluated on a compound-by-compound basis. In cases where cluster ion formation is predominant, the analyte could be detected as a reagent ion cluster rather than an [M $\mathrm{H}^{-}$ion. In any event, the reproducibility of cluster formation would have to be determined to assess the analytical utility.

Positive ion formation. Although many of the test analytes were expected to form negative ions more readily than positive ions, all were tested in positive APCI to determine which mode provided the more intense signal (i.e., greater peak area). First, the gas-phase reagent cations were determined for the $10-\mathrm{mM}$ formic acid, 10-mM ammonium acetate, and 100-mM ammonium acetate mobile phases. The formic acid mobile phase displayed reagent ions at $m / z 42,60,83,88,101$, and 129 with relative intensities of $1.0: 1.5: 1.6$ : $0.2: 1.5: 0.6$, respectively. The ion at $m / z 42$ represented protonated acetonitrile and the other ions corresponded to clusters of $\mathrm{m} / z \mathbf{4 2}$ with water, formic acid, and additional acetonitrile molecules. Additional ions at $\mathrm{m} / z 59$ and 100 (relative intensities of 1.6 and 1.1, respectively) corresponded to ammoniated acetonitrile 
and a bis-acetonitrile-ammonium cluster, respectively, and were formed from residual ammonium ions in the HPLC system. An ion also was observed at $m / z 56$ (which could represent $\mathrm{N}_{4}^{+}$[13]), but the identity of this ion was not determined here with certainty. (The reagent ion spectrum for $50 \%$ aqueous acetonitrile was qualitatively and quantitatively very similar, but lacked the formic acid cluster ions.) The reagent ion mass spectra for the 10 - and $100-\mathrm{mM}$ ammonium acetate mobile phases were very similar to each other. Reagent ions at $m / z 18,59,100,118$, and 129 were present in a ratio of $0.02: 1.0: 1.2: 0.1: 0.5$ for the $10-\mathrm{mM}$ ammonium acetate mobile phase and 0.02:1.0:1.2: $0.3: 0.2$, respectively, for $100-\mathrm{mM}$ ammonium acetate. The trace level signal at $m / z 18$ represented free ammonium ion and the ions at $m / z 59,100$, and 118 corresponded to ammonium clusters with acetonitrile and water. The ion at $m / z 129$ corresponded to a protonated bis-acetonitrile-formic acid cluster.

For each analyte, the peak area for the positive ion signal was compared to that obtained in the negative ion mode using $N$-methylmorpholine. Positive ion formation was evaluated using the $10-\mathrm{mM}$ formic acid mobile phase, which lacked amines that could compete for protons. In addition, the proton affinity of formic acid was lower than that of protonated acetonitrile, as well as other aliphatic carboxylic acids (which including acetic acid), benzoic acid, and phenol (Table 2), which suggests that formic acid might not compete with the analytes for available protons. Some of the analytes that gave a response with formic acid also were tested using the ammonium acetate mobile phase. The results for $[\mathrm{M}+\mathrm{H}]^{+}$ion formation are summarized in Table 3. An obvious candidate for formation of positive ions was piperidinepropionic acid. Although the optimal signal for piperidinepropionic acid in the negative APCI mode was observed using $N$-methylmorpholine, the signal observed in positive APCI was much greater with either formic acid or ammonium acetate. The best response for piperidinepropionic acid was observed with $100-\mathrm{mM}$ ammonium acetate. The proton affinity of the tertiary amine in piperidinepropionic acid was much greater than that of ammonia [16, 17] or the ammonia-solvent cluster ions, and the compound was protonated efficiently. The positive ion signals for diclofenac, indomethacin, and 4-methoxycinnamylhydroxamic acid with the $10-\mathrm{mM}$ formic acid mobile phase were comparable to the responses observed in the negative ion mode with $N$-methylmorpholine. The positive ion signals for these compounds with $10-\mathrm{mM}$ ammonium acetate were either very weak or not detectable, which is consistent with inefficient proton transfer from ammonium-solvent clusters to these weakly basic compounds. The response of phenols in positive APCI with the formic acid mobile phase was less than that observed in negative APCI with $N$-methylmorpholine, and the response with ammonium acetate was weaker still. Trifluoromethoxybenzohydroxamic acid did not form positive ions to an appreciable degree, even when competing amines were absent from the mobile phase. The response of the other carboxylic acid-containing analytes was poor even with the formic acid mobile phase. Even though the proton affinities of the carboxylic acid and phenolcontaining analytes were likely higher than that of acetonitrile (Table 2), the abundant clusters of protonated acetonitrile may be less acidic than unclustered protonated acetonitrile [13]. Thus the acetonitrile clusters may not be acidic enough to transfer a proton to these analytes efficiently. Alternatively, the proton transfer reaction was likely to be reversible and thermodynamically controlled as described previously $\left(\mathrm{B}+\left[\mathrm{CH}_{3} \mathrm{CN}+\mathrm{H}\right]^{+} \rightleftharpoons \mathrm{BH}^{+}+\mathrm{CH}_{3} \mathrm{CN}\right.$ or $\mathrm{B}+\left[2 \mathrm{CH}_{3} \mathrm{CN}\right.$ $\left.+\mathrm{H}]^{+} \rightleftharpoons \mathrm{BH}^{+}\left[\mathrm{CH}_{3} \mathrm{CN}\right]+\mathrm{CH}_{3} \mathrm{CN}\right)$. The equilibrium of this reaction could be dramatically effected by the extremely high concentration of acetonitrile in the source (because it comprises $50 \%$ of the mobile phase), which would drive the reverse reaction. The possibility that these analytes may preferentially form clusters with protonated acetonitrile rather than an $[\mathrm{M}+\mathrm{H}]^{+}$ ion, must also be acknowledged. The poor response of acetylsalicylic acid may have been due at least in part to extensive fragmentation of the $[\mathrm{M}+\mathrm{H}]^{+}$ion via loss of $\mathrm{CH}_{2} \mathrm{CO}$.

\section{Chromatography Under Basic Conditions}

Since the ionization efficiency of many of these acidic analytes was greater when the $10-\mathrm{mM} \mathrm{N} \mathrm{N}$-methylmorpholine mobile phase was used, chromatography that used this $\mathrm{pH}$ modifier was investigated. Several different types of reverse phase HPLC columns that are compatible with alkaline mobile phases are commercially available. A column that we found to be compatible with aqueous amine modifiers was the AluspherRP column, which utilizes an alumina support with an octyl bonded phase. Figure 4 displays single ion monitoring chromatograms for several analytes obtained by using a gradient elution with aqueous $10-\mathrm{mM} \mathrm{N}$-methylmorpholine and acetonitrile. Chromatography also was evaluated by using $10-\mathrm{mM}$ triethylamine or $10-\mathrm{mM}$ ammonium hydroxide instead of $N$-methylmorpholine, but the best chromatographic retention (i.e., the longest retention time) was observed with $N$-methylmorpholine, which may act by ion pairing of the $N$ methylmorpholinium ion with the deprotonated acids. Although the different amine modifiers had little effect on the retention of estradiol, the other more acidic analytes were retained 5.4-8.6 min longer with $N$ methylmorpholine compared to triethylamine or ammonium hydroxide. This difference is important for chromatography of relatively polar analytes, such as 3-(4-methoxyphenyl)propionic acid which was not retained on the column with triethylamine or ammonium hydroxide, but was retained with $N$-methylmorpholine. Triethylamine also was found to be unacceptable for extended use because it produced a brown residue on the corona discharge needle in the APCI 
Table 3. Ionization of model compounds by positive ion APCI in the presence of various buffers (mixed with acetonitrile $1: 1$ )-comparison with the negative APCI results ${ }^{\mathrm{a}}$

\begin{tabular}{|c|c|c|c|c|}
\hline Compound & {$\left[\mathrm{M}+\mathrm{H}^{+}\right.$} & $\begin{array}{c}\text { Formic } \\
\text { acid } \\
(10 \mathrm{mM})\end{array}$ & $\begin{array}{c}\text { Ammonium } \\
\text { acetate } \\
(10 \mathrm{mM})\end{array}$ & $\begin{array}{c}\text { Ammonium } \\
\text { acetate } \\
\text { (100 mM) }\end{array}$ \\
\hline & 155 & $1 \%$ & $N D^{D}$ & ND \\
\hline & 181 & $1 \%$ & ND & ND \\
\hline & 207 & $1 \%$ & ND & ND \\
\hline & 181 & $3 \%$ & ND & ND \\
\hline & 273 & $40 \%$ & $3 \%$ & ND \\
\hline & 165 & $9 \%$ & $6 \%$ & ND \\
\hline & 196 & $131 \%$ & $2 \%$ & ND \\
\hline & 138 & $<1 \%$ & ND & ND \\
\hline & 222 & $3 \%$ & ND & ND \\
\hline & 158 & $327 \%$ & $587 \%$ & $815 \%$ \\
\hline & 296 & $111 \%$ & ND & ND \\
\hline & 358 & $84 \%$ & $<1 \%$ & ND \\
\hline
\end{tabular}

Peak area values by positive $A P C I$ are expressed as a percent, relative to the areas observed using $\mathrm{N}$-methylmorpholine in negative APCl.

${ }^{\mathrm{b}} \mathrm{ND}=$ not determined.

source after only 1-2 h of operation. Neither $N$-methylmorpholine nor ammonium hydroxide displayed this problem. One important point to consider when evaluating the possibility of using alkaline mobile phases is the stability of the analytes at higher pHs. Base-labile compounds could degrade during the chromatographic separation prior to mass spectral detection.

\section{Conclusions}

The HPLC mobile phase, as well as the mass spectrometry conditions used in negative APCI, can have a profound effect on sensitivity. Phenyl acetic acids readily eliminated $\mathrm{CO}_{2}$ in the source of the mass spectrometer at higher orifice potentials that can decrease the 
m/2 179 3-[4-Methoxyphenyl]propionic acid

959,400

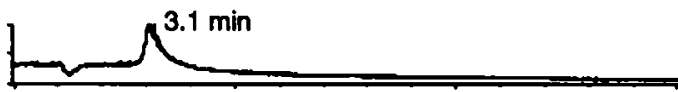

$\mathrm{m} / \mathbf{z} 356$ Indomethacin
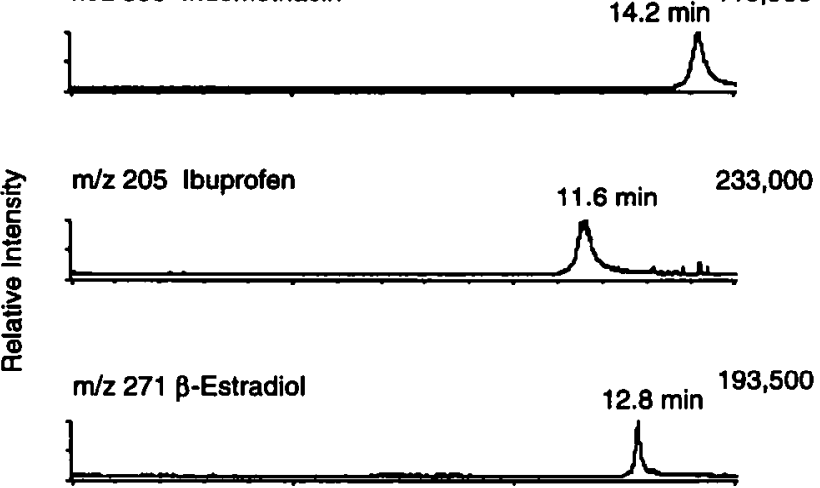

$\mathrm{m} / \mathrm{z} 294$ Diclofenac

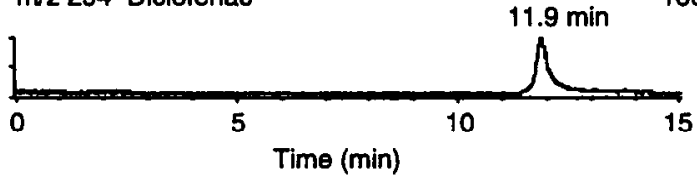

Figure 4. Reconstructed ion chromatograms for acidic model analytes eluted by using an HPLC gradient system with $10-\mathrm{mM}$ aqueous $\mathrm{N}$-methylmorpholine and acetonitrile. Analytes were injected as a mixture $(10 \mu \mathrm{L})$ that contained 3-[4methoxyphenyl]propionic acid (50 ng), indomethacin (50 ng), ibuprofen (20 ng), $\beta$-estradiol ( $200 \mathrm{ng}$ ), and diclofenac (50 ng).

intensity of the $\left[\mathrm{M}-\mathrm{H}^{-}\right.$ions. Buffers used in the mobile phase also can have a dramatic effect on ionization and even can quench ionization completely. Of the $\mathrm{pH}$ modifiers tested, formic acid had the most detrimental effect on the formation of negative ions. Thus, for initial development of analytical methods via negative APCI, a mobile phase that contains formic acid as a $\mathrm{pH}$ modifier should be avoided. Neutral molecules with protic functional groups frequently do not require a buffer to obtain good chromatographic peak shape and should show efficient ionization with a mixture of water-acetonitrile as an HPLC mobile phase. For acidic compounds, use of a mobile phase that contains a dilute acetate buffer (such as 10-mM ammonium acetate), rather than formic acid, would be a better starting point because this buffer worked fairly well with most analytes tested. Alternatively, other ionization methods also should be considered. For example, some analytes that may at first appear to be candidates for negative APCI, may show good sensitivity with negative electrospray ionization or may be analyzed with adequate sensitivity by using positive electrospray ionization via formation of an ammonium adduct $[\mathrm{M}+$ $\left.\mathrm{NH}_{4}\right]^{+}$. For analytes that do not form positive ions readily and that do not ionize well by using electro- spray, negative APCI with a basic mobile phase that contains a volatile amine may provide useful results. Clearly, an understanding of the effect that an HPLC mobile phase can have on ionization can aid in the selection of an appropriate mobile phase and reduce the trial-and-error associated with method development.

\section{Acknowledgment}

The authors are grateful to Dr. Gerald Rhodes for many helpful discussions and his dedicated support throughout the course of these studies.

\section{References}

1. Covey, T. R.; Lee, E. D.; Bruins, A. P.; Henion, J. D. Anal. Chem. 1986, 58, 1451A-1461A.

2. Bruins, A. P. Mass Spectrom. Rev. 1991, 10, 53-77.

3. Covey, T. R.; Lee, E. D.; Henion, J. D. Anal. Chem. 1986, 58, 2453-2460.

4. Muck, W. M.; Henion, J. D. Biomed. Environ. Mass Spectrom. 1990, 19, 37-51.

5. Fouda, H.; Nocerini, M.; Schneider, R.; Gedutis, C. J. Am. Soc. Mass Spectrom. 1991, 2, 164-167.

6. Gilbert, J. D.; Hand, E. L.; Tuan, A. S.; Olah, T. V.; Covey, T. R. Biol. Mass Spectrom. 1992, 21, 63-68.

7. Gilbert, J. D.; Olah, T. V.; Barrish, A.; Greber, T. F. Biol. Mass Spectrom. 1992, 21, 341-346.

8. Avery, M. J.; Mitchell, D. Y.; Falkner, F. C.; Fouda, H. G. Biol. Mass Spectrom. 1992, 21, 353-357.

9. Dzidic, I.; Carroll, D. I.; Stillwell, R. N.; Horning, E. C. Anal. Chem. 1976, 48, 1763-1768.

10. Lane, D. A.; Thomson, B. A.; Lovett, A. M.; Reid, N. M. Adv. Mass Spectrom. 1980, 8B, 1480-1489.

11. Dzidic, 1.; Carroll, D. I.; Stillwell, R. N.; Horning, M. G.; Horning, E. C. Adv. Mass Spectrom. 1978, 7, 319.

12. Bruins, A. P. Adv. Mass Spectrom. 1986, 10, 119-131.

13. Sunner, J.; Nicol, G.; Kebarle, P. Anal. Chem. 1988, 60, 1300-1307.

14. Sunner, J.; Ikonomou, M. G.; Kebarle, P. Anal. Chem. 1988, 60, 1308-1313.

15. Nicol, G.; Sunner, J.; Kebarle, P. Int. J. Mass Spectrom. Ion Processes 1988, 84, 135-155.

16. Harrison, A. G. Chemical Ionization Mass Spectrometry, 2nd ed.; CRC Press: Boca Raton, FL, 1992.

17. Lias, S. G.; Bartmess, J. E.; Liebman, J. F.; Holmes, J. L.; Levin, R. D.; Mallard, G. W. J. Phys. Chem. Ref. Data 1988, 17, Suppl. 1.

18. Horning, E. C.; Carroll, K. I.; Dzidic, I.; Haegele, K. D.; Horning, M. G.; Stillwell, R. N. J. Chromatogr. 1974, 99, 13-21.

19. Dzidic, I.; Carroll, K. I.; Stillwell, R. N.; Horning, E. C. J. Am. Chem. Soc. 1974, 96, 5258-5259.

20. Dzidic, I.; Carroll, K. I.; Stillwell, R. N.; Horning, E. C. Anal. Chem. 1975, 47, 1308-1312.

21. Bartmess, J. E.; Scott, J. A.; McIver, R. T. J. Am. Chem. Soc. 1979, 101, 6056-6063.

22. Graul, S. T.; Schnute, M. E.; Squires, R. R. Int. J. Mass Spectrom. Ion Processes 1990, 96, 181-198.

23. Caldwell, G.; Renneboog, R.; Kebarle, P. Can. J. Chem. 1989, 67, 611-618.

24. Winkler, F. J.; Stahl, D. J. Am. Chem. Soc. 1979, 101, 3685-3687. 